\title{
ORIGINAL
}

PROF-923

\section{CARCINOMA OF CERVIX}

\author{
DR. MUHAMMAD IKRAM MBBS, MCPS, FCPS \\ Senior Registrar \\ Sheikh Zayed Medical Complex, Lahore
}

DR. WASIM TALIB MBBS, MCPS, FCPS

Assistant Professor

Lahore Medical College, Lahore

DR. SADIA CHATHA MBBS, FCPS

Senior Registrar

Services Hospital, Lahore

\author{
Dr. Roohi Saeed MBBS, DA, MCPS, FRCOG \\ Associate Professor \\ Sheikh Zayed Medical Complex, Lahore
}

\author{
Prof. M. Saeed MBBS, MD, FRCOG \\ Professor \& Head of Department \\ Sheikh Zayed Medical Complex, Lahore \\ Copyrights: 8 June, 2005.
}

\begin{abstract}
Objective: To study the risk factors, clinical presentation and outcome of management in patients of carcinoma of cervix for one year. Design: Retrospective descriptive study. Place \& Duration of Study: Department of Obstetrics and Gynaecology, Sheikh Zayed Federal Postgraduate Medical Institute and Hospital, Lahore from January 1998 to December 2000. Subjects \& Methods: All the patients of carcinoma of cervix diagnosed during the period of study were included. Relative information were filled in a proforma. Out of 32 cases, 30 cases were selected for study as 2 patient did not report back after initial diagnosis. Results: There were $80 \%$ patients above the age of 40 years. $90 \%$ patients were married below the age of 20 years. There was obvious correlation of carcinoma cervix with low socioeconomic status and high parity. Foul smelling bloody vaginal discharge, post-coital bleeding, post-menopausal bleeding and irregular periods were the most common symptoms. Most of the patients presented late, so $57 \%$ patients were referred for radiotherapy alone. Surgery alone was possible in only 5 patients and combination of surgery and radiotherapy in 7 patients. Follow up attendance of patients was extremely poor and there was 1 recurrence after primary treatment with radical surgery and radiotherapy. Conclusion: Lack of effective screening programme and awareness of patients have led to the delay in diagnosis. All women of reproductive age, peri-and post-menopausal age groups, para 5 and above, low socioeconomic status and teenage marriages should undergo regular screening for carcinoma of cervix at their own locality.
\end{abstract}

Key words: $\quad$ Carcinoma cervix, Post coital bleeding, Post menopausal bleeding, Radiotherapy.

\section{INTRODUCTION}

Carcinoma of the cervix continues to be the second commonest female cancer worldwide, with only breast cancer occurring more commonly ${ }^{1}$, while it is the commonest cancer among females in developing countries. In the developing countries about $75 \%$ patient 
of carcinoma of cervix present with an advance stage which is the converse of presentations in the developed countries where $75 \%$ present early and cure can be realistically expected.

Progress in the knowledge of cervical cancer, techniques for early detection and screening has developed in the past decades. Better understanding of the pathological types and its factors have been defined leading to individualization of treatment. Carcinoma of the cervix is the commonest cancer among the genital tract malignancies in Pakistan². Over the past decades however, ovarian cancer has also tended to rise ${ }^{3,4}$. Most of the cases of the carcinoma of cervix come for treatment in this country at such an advanced stage of the disease, that curative treatment becomes unsatisfactory. Early detection could provide better and more effective treatment at lower costs. It also could offer these women a better prognosis regarding survival and quality of life.

\section{MATERIALS AND METHODS}

All the patients diagnosed as carcinoma of cervix during the period of study at Shiekh Zayed Hospital, Lahore were included. There were two patients who were diagnosed of having carcinoma of cervix and surgery was planed but they did not report back so they were excluded from the study.

\section{METHODOLOGY}

Patients were admitted through outpatient department or emergency suspected of having carcinoma of cervix or referred with diagnosis of carcinoma of cervix from other hospitals. All the cases were reviewed. The data collected from the files of the patients included;

Age at presentation and marriage, registration number, address, socioeconomic status, reproductive status, marital status, menstrual history, history of smoking and contraceptives, presenting complaints, examination findings, laboratories findings, stage of the diagnosed and histopathology reports, treatment modalities given and 1 year follow up.

\section{STATISTICAL ANALYSIS}

Simple statistical analysis of the data was done and results were tabulated.

\section{RESULTS}

This study is based on the analysis of data regarding 30 consecutive patients with carcinoma of cervix. Table-I shows that, age above 40 years, early age at marriage, low socioeconomic status, high parity, irregular cycle and post-menopausal women were risk factors associated with carcinoma of cervix as there were $80 \%, 90 \%, 80 \%$, $80 \%, 50 \%$, and $40 \%$, patients in each group respectively.

Table-I. Risk factors of cases with Carcinoma cervix

$$
(n=30)
$$

\begin{tabular}{|c|c|c|}
\hline Risk Factor & No. of patients & $\%$ Age \\
\hline $\begin{array}{c}\text { Age } \\
\text { Upto 40 yrs } \\
>40 \text { yrs }\end{array}$ & 6 & $20 \%$ \\
\hline $\begin{array}{c}\text { Age at marriage } \\
<20 \text { yrs }\end{array}$ & 24 & $80 \%$ \\
$>20$ yrs & 3 & $10 \%$ \\
\hline Monthly Income & & \\
$<$ Rs. 3000/m & & \\
$>$ Rs. 3000/m & 24 & $80 \%$ \\
\hline Parity & 6 & $20 \%$ \\
\hline para 5 & & \\
$<$ para 5 & 24 & $80 \%$ \\
\hline Menstruation & 6 & $20 \%$ \\
\hline Regular & & \\
Irregular & 3 & $10 \%$ \\
Post menopausal & 15 & $50 \%$ \\
\hline Multiple sexual partner & 12 & $40 \%$ \\
\hline Smoking & 0 & $0.0 \%$ \\
\hline Oral contraceptive & 1 & $3.33 \%$ \\
\hline & 2 & $6.66 \%$ \\
\hline
\end{tabular}

Table-Il shows the main presenting complaints. All the above complaints points towards presentations of the patients at late stage of the disease. 


\begin{tabular}{|c|c|c|}
\hline \multicolumn{2}{|c|}{$\begin{array}{c}\text { Table II. Presenting complaints of the patients with } \\
\text { carcinoma of the cervix }\end{array}$} & \% Age \\
\hline Presentation complaints & No. of patients & 70 \\
\hline $\begin{array}{c}\text { Foul smelling blood vaginal } \\
\text { discharge }\end{array}$ & 21 & 50 \\
\hline Post-coital bleeding & 15 & 40 \\
\hline Post-menopausal bleeding & 12 & 33.33 \\
\hline Irregular vaginal bleeding & 10 & 30 \\
\hline Pain lower abdomen & 9 & 10 \\
\hline Backache & 3 & 10 \\
\hline Abdominal distension & 3 & \\
\hline
\end{tabular}

Table III. Staging of patients with carcinoma of the cervix $(n=30)$

\begin{tabular}{|c|c|c|}
\hline Stage & No. of patients & $\%$ age \\
\hline 0 (carcinoma in situ) & 3 & 10 \\
\hline I-A & 2 & 6.66 \\
\hline I-B & 0 & 0.00 \\
\hline II-A & 6 & 20 \\
\hline II-B & 9 & 30 \\
\hline III-A & 6 & 20 \\
\hline III-B & 3 & 10 \\
\hline IV-A & 0 & 0.00 \\
\hline IV-B & 1 & 3.34 \\
\hline Total & 30 & 100 \\
\hline
\end{tabular}

Table-III shows that there were $82.5 \%$ patients who are in stage II and above and $90 \%$ were in the invasive stage of carcinoma of cervix again signifying the late presentation of patients.

Table-IV shows that there were only $10 \%$ patients who underwent total abdominal hysterectomy and bilateral salpingo-oophorectomy (TAH+ BSO), 6.6\% patient underwent radical surgery (Werthiem's hysterectomy),
$56.6 \%$ patients underwent radiotherapy alone and $23.3 \%$ patients underwent combined treatment (radical surgery and radiotherapy).

Table- $V$ shows that $83.3 \%$ patients were suffering from squamous cell carcinomas, $10 \%$ were adenosquamous carcinoma while $6.6 \%$ were adenocarcinomas.

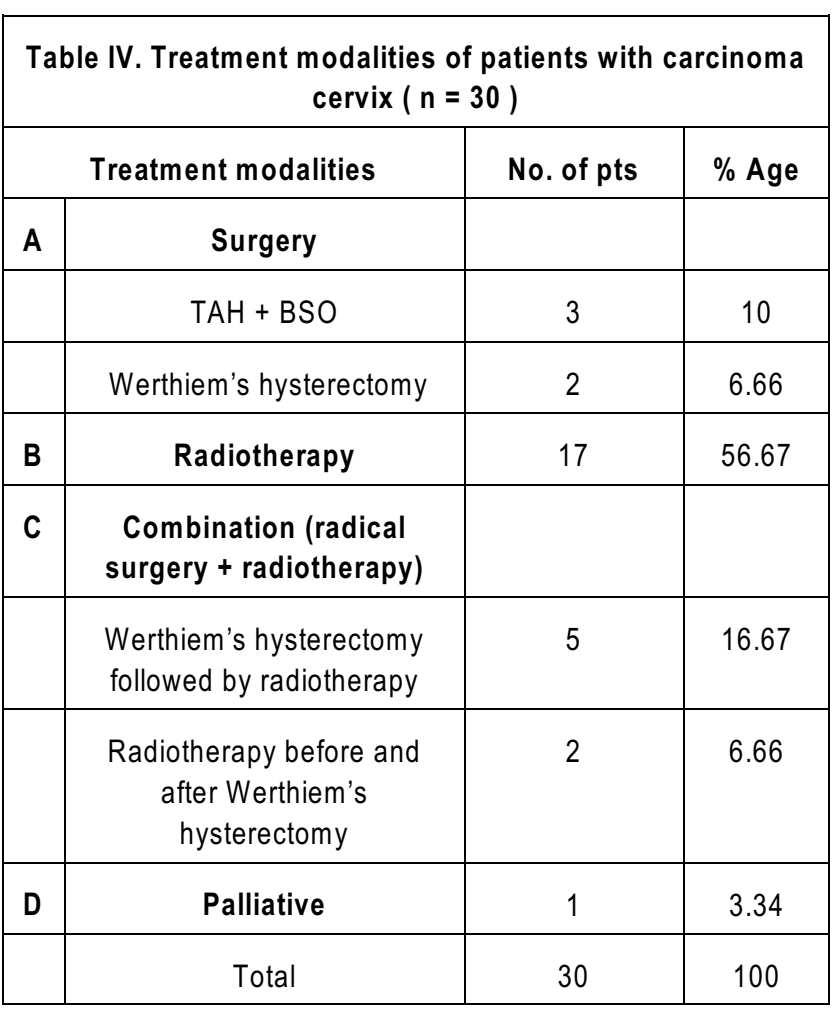

\begin{tabular}{|l|l|l|}
\hline \multicolumn{3}{|c|}{$\begin{array}{c}\text { Table V. Histopathological diagnosis of the patients with } \\
\text { carcinoma of cervix }(\mathrm{n}=30)\end{array}$} \\
\hline Histopathological diagnosis & $\begin{array}{l}\text { No. of } \\
\text { patients }\end{array}$ & $\%$ Age \\
\hline Squamous cell carcinoma & 25 & 83.33 \\
\hline Adenosquamous carcinoma & 3 & 10.00 \\
\hline Adenocarcinoma & 2 & 6.67 \\
\hline Total & 30 & 100 \\
\hline
\end{tabular}

\section{DISCUSSION}

In the present study the peak incidence of carcinoma of the cervix was found in age group 41-50 years. This 
observation is similar to those of Riaz Ahmed Bhutta et $\mathrm{al}^{5}$ and Roohi and Sahi ${ }^{6}$, but differ from Parveen et al ${ }^{7}$ and Latifa Shamsuddin et $\mathrm{al}^{8}$ who reported more cases in early age groups. The number of cases after the age of 60 years and above are less in this study as compared to those of Dumn and Schweitzer and El-Senoussi et al ${ }^{9}$. This difference may be due to less life expectancy in our country.

Early age at marriage was the other prominent finding in the study. This finding is in complete agreement with study by Varghese et $\mathrm{al}^{10}$ in which early age at marriage was found to be the single best predictor of the disease status. On reviewing the studies on the association of age at marriage observed that women marrying earlier than 17 years are at particularly higher risk of developing cervical cancer ${ }^{11}$ because adolescent cervix is associated with a higher risk of cervical neoplasia compared with later life.

In present study $80 \%$ patients belonged to low socioeconomic class. These findings are slightly different to those of Varghese et $\mathrm{al}^{10}$ in which $57 \%$ of the patients were in the low income category whose monthly income was under US $\$ 15$. But if the criteria for low socioeconomic group is selected as under 3000 per month as in this study, both the studies coincide. This study coincide with the study by Gharoro et al ${ }^{12}$ in which poverty featured prominently.

High parity was the prominent finding in the study. This finding is in complete agreement with studies by Kjaer in Denmark $^{13}$, Gharoro in Benin city-Nigeria ${ }^{12}$ and Latifa Shamsuddin in Bangladesh ${ }^{8}$.

In the study multiple sexual partners, smoking and oral contraception were not important risk factors as none, 1 and 2 patients were present in each group respectively. These findings are similar with the study by Gharoro in Nigeria $^{12}$ in which smoking and multiplicity of sexual partners were rather uncommon. While this study totally differ regarding above findings, with Kjaer in Denmark ${ }^{13}$ in which multiple sexual partners, oral contraceptive use and smoking were important risk factors.
As far as the presenting complaints are concerned, the commonest complaint in the study was foul smelling bloody vaginal discharge. While in a study by Shamsuddin et $\mathrm{al}^{8}$ the chief complaint was excessive vaginal discharge in $50.49 \%$ of the patients. In another study by Hill and Galante ${ }^{14}$, the commonest complaint was irregular vaginal bleeding or blood stained discharge on coitus or straining. Probably the difference in this study and by Edward and Hill is due to late presentation of the patients in our setup when the cervical growth becomes infected leading to foul smelling bloody discharge.

This study completely differ with the study by Latifa Shamsuddin $^{8}$ and Cherechi et $\mathrm{al}^{15}$ where most of the patients were diagnosed in pre-invasive stage. This study differ with the other two studies because of lack of screening for cervical cancer in our country which fails to diagnose the disease at an earlier stage.

Conservative surgery was done in $10 \%$ patients while $56 \%$ patients had radiotherapy alone. These findings differ from study by Jackson et al ${ }^{16}$ in which $21.29 \%$ patients had conservative surgery. This is because in our region most of the patients come at a later stage when conservative or radical surgery is not possible as a primary treatment.

In this study $83.83 \%$ patients had squamous cell carcinoma. Almost similar results were found in studies by Bhutta et $\mathrm{al}^{5}$ from Multan and by El-Senoussi et $\mathrm{al}^{9}$ in Saudi Arabia.

While comparing age of patients and type of carcinoma cervix. Adenocarcinoma was found in younger age group in this study as both the cases were between 30-40 years of age. This finding is exactly the same as found Cakarverty et $\mathrm{al}^{17}$ in their studies in which adenocarcinoma cervix showed statistically significant preponderance in comparatively younger age group.

As far as disease relapse is concerned there was only $3.33 \%$ patients in this study. While in a study by Cherchi et $\mathrm{al}^{15}$ the relapse incidence (follow-up 8-118 months) 
was $14.6 \%$. This difference between the two studies is due to shorter follow-up in which $80 \%$ patients escaped.

\section{CONCLUSIONS}

The present study concludes that.

The women above 40 years of age are more prone to develop carcinoma of cervix.

Foul smelling bloody discharge, post-coital bleeding, post-menopausal bleeding, irregular vaginal bleeding and pain lower abdomen were the cardinal symptoms for carcinoma cervix.

Adenocarcinoma of cervix showed preponderance in comparatively younger age group. Lack of effective screening programme and awareness on the part of patients have led to the delay in diagnosis and later stage presentation. Response of follow-up was very poor.

\section{REFERENCE}

1. Shafi MI, Jorden JA. Management of pre-invasive lesions of the cervix In: Shingleton HM, Fowler WC Jorden JA, Lawerence WD (eds). Gynaecological oncology current diagnosis and treatment. London: Saunders, 1996; pp. 43-50.

2. Jafaery NA, Zaidi SHM. Cancer in Pakistan. J Pak Med Assoc 1987; 37: 178-183.

3. Ahmed M, Khan AH, Mansoor A. The pattern of malignant tumours in Northern Pakistan. J Pak Med Assoc 1991; 41:270-73.

4. Saeed M, Khalid K, Iffar R, et al. A clinicopathologica analysis of ovarian tumours. J Pak Med Assoc 1991; $41: 161-164$

5. Bhutta RA, Khan UA, Choudhry MA. Carcinoma cervix: A retrospective study. JPMA J Pak Med Assoc 1999; 49:36-7.

6. Roohi M, Sahi SJ. Incidence of cervical intra-epithelial neoplasia in Faisalabad. Pak J Med Res 1993; 32:162
65.

7. Parveen SA, Akhtar N, Shahid MA. Radiotherapy of cervical cancer, experience with combined brachytherapy and external beam therapy. Pak J Med Res 1995; 34: 95-98.

8. Shamsuddin L, Chowdhury TA, Azim A, Nohar Rahman AJE. Clinical down staging of cancer cervix with cytology. Bangladesh med Res Counc Bull 1995; 21 : 108-114.

9. El-Senoussi M, Bakri Y, Amer MH, De Vol EB. Carcinoma o the uterine cervix in Saudi Arabia: experience in the management of 164 patients with stage I and II disease. Int J Radiant Oncol Biol Phys 1998; 42: 91-100.

10. Cherian Varghese, et al. Risk factors for cervical dysplasia in Karala, India. Bulletin of the World Health Organization, 1999; 77: 281-83.

11. Brinton et al. Parity as a risk factor. Am J Epi 1986; $130: 486-496$

12. Gharoro EP, Abedi HO, Okpere EE. Carcinoma of the cervix: aspects of clinical presentation and management in Benin city. Int J Gynaecol Obstet 1999; 67: 51-3.

13. Kjaer SK. Risk factor for cervical neoplasia in Denmark. APMIS 1998; 80: 1-41.

14. Hill EC, Galante M. Radical surgery in the management of clear cell adenocarcinoma of the cervix and vagina in young women. Am J Obstet and Gynaecol 1981; 140:221.

15. Cherchi PL et al. The management of cervical carcinoma in the Gynacologic and Obstetric Institute of Sassari in ten years period 1980-89. Eur J Gynaecol Oncol; 12:83-6.

16. Jackson $S$, et al. The management of cervical carcinoma within the South West Region of England. Br J Obstet and Gynaecol 1997; 140: 140-44.

17. Chakraverty R, Gupta A, Bhowmik KT. Review of carcinoma cervix cases - epidemoiological considerations I. J Idian Med Assoc 1998; 96: 8-9. 